\title{
10.5005/jp-joumals-10001-1065 CASE REPORT
}

\section{Oral Melanosis}

\author{
${ }^{1}$ Harvinder Kumar, ${ }^{2}$ Pankaj Chaturvedi \\ ${ }^{1}$ Associate Professor, Department of ENT, Maharaja Agrasen Medical College, Hisar, Haryana, India \\ ${ }^{2}$ Associate Professor, Department of Head and Neck Oncology, Tata Memorial Hospital, Mumbai, Maharashtra, India
}

Correspondence: Harvinder Kumar, Associate Professor, DepartmentofENT, Maharaja Agrasen Medical College, Hisar, Haryana India, e-mail: drharvinderent@ gmail.com

\section{ABSTRACT}

There is very little information in literature about oral melanosis not associated with racial pigmentation or secondary to other syndromes. Various stimuli that can result in an increased production of melanin at the level of mucosa include trauma, hormones, radiation and medications. Three such cases are reported in which stimulus for genesis of melanosis was mechanical trauma in form of smoking.

Keywords: Oral, Melanosis, Smoking.

\section{INTRODUCTION}

In our clinical practice we see many cases of oral pigmentary lesions, the etiology of which ranges from physiologic changes (e.g. racial pigmentation) to manifestations of systemic illnesses (e.g. A ddison's disease) and malignant neoplasms (e.g. melanoma and Kaposi's sarcoma). There is very little information in literature about oral melanosis not associated with racial pigmentation or secondary to other syndromes. We are reporting three such cases of oral melanosis which presented at different subsites in contrast to sites commonly seen in literature. Here is review of literature of oral melanosis in terms of its etiology, pathophysiology, clinical presentation and differential diagnosis.

\section{CASE REPORT}

First case was a 38-year-old female who presented with brown pigmentation on ventral aspect of tongue (Fig. 1) and the history of tobacco use in form of chewing was present for a period of 6 years. Second case was a 54 -yearold male, presented with brown pigmentation on dorsum of tongue (Fig. 2) and history of smoking for the last more than 15 years. Third case was 59-year-old male, presented with brown black pigmentation on inner aspect of lip mucosa (Fig. 3). Patient was chronic smoker for last 20 years. A II cases were clinically asymptomatic. In all cases, biopsy of the lesion was taken to confirm the diagnosis and to rule out oral melanoma as the lesions were present on subsides other than commonly seen in melanosis. Reassurance was given to all the cases. Lesion reduced after one year of stopping smoking.

\section{DISCUSSION}

Oral melanosis is a benign focal pigmentary (brown or black) lesion of the oral cavity mucosa, though cases of melanosis have been reported on sinonasal, pharyngeal, conjunctival and laryngeal mucosa also. Oral pigmentation is caused by

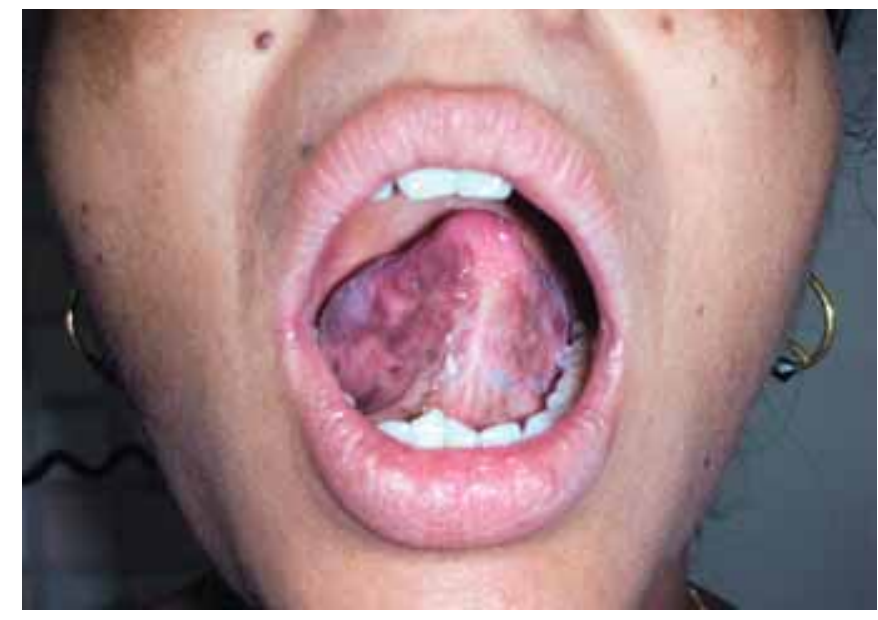

Fig. 1: Changes of oral melanosis at ventral aspect of tongue (case 1 )

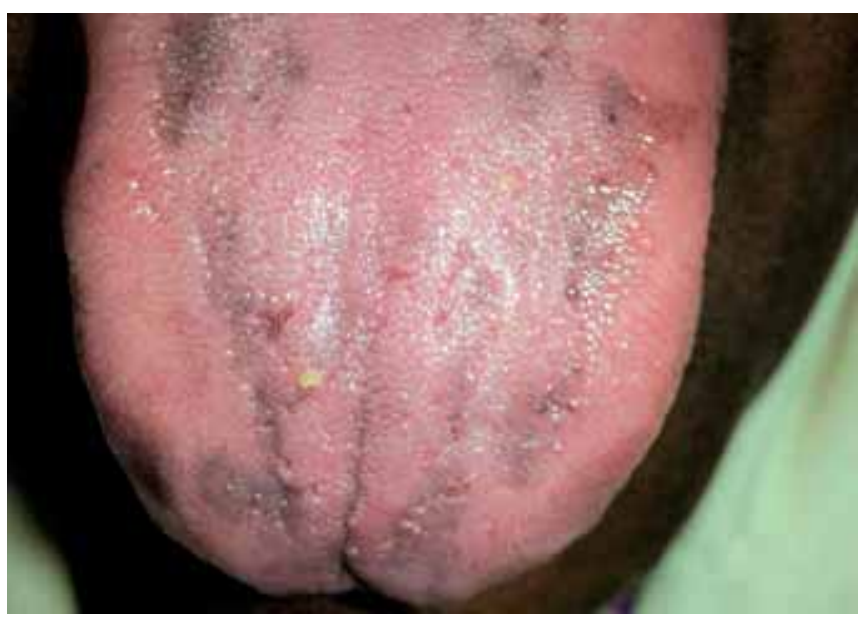

Fig. 2: Changes of oral melanosis at dorsum of the tongue (case 2)

exogenous (foreign body implantation) and endogenous pigmentation. Primary pigments responsible for endogenous pigmentation include melanin, melanoid, oxyhemoglobin, reduced hemoglobin and carotene. Out of these pigments, melanin is the most common endogenous pigment which is 


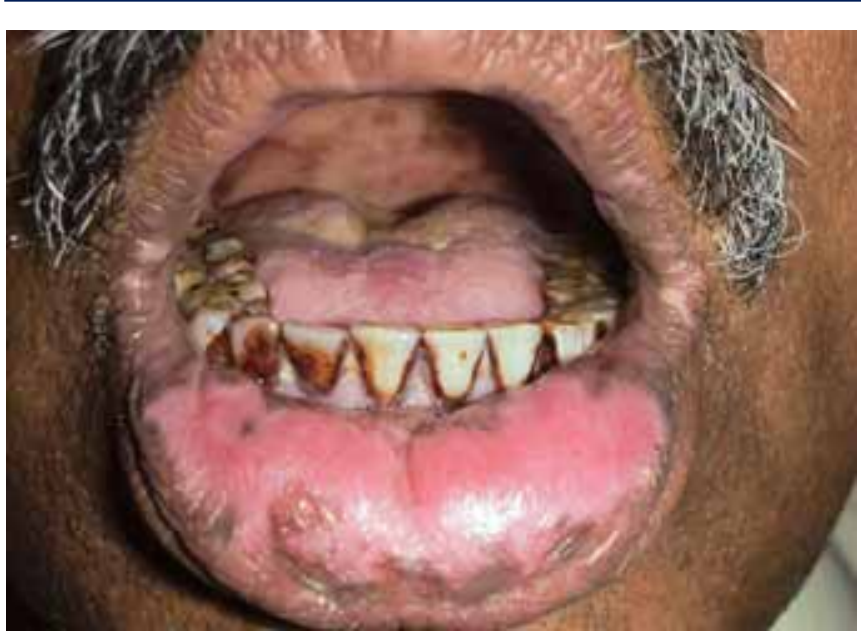

Fig. 3: Changes of oral melanosis at inner aspect of lip (case 3)

a nonhemoglobin derived brown pigment and is produced by melanocytes present in the basal layer of the epithelium. ${ }^{1}$ $M$ elanocytes were first identified in the oral epithelium by Becker in 1927 and a few years later they were isolated from samples of gingival tissue by Laidlaw and Cahn. ${ }^{2}$ During early intrauterine life, melanoblasts (precursor of melanocyte) migrate from the neural crest to the epidermis and hair follicles. L ater they differentiate into dendritic cells and appear in head and neck region after approximately 10 weeks of gestation. M elanocytic dendrites reach a number of keratinocytes in the close vicinity, and through these dendrites, melanin is transported and transmitted to these epithelial cells, process called melanogenesis. The normal melanocytes of the oral mucosa have a small, round nucleus and a small amount of a clear cytoplasm. The number of melanocytes in the mucosa corresponds numerically to that of skin but with a reduced activity. ${ }^{3}$ The color of the mucosa may be brown, blue, grey or black, depending on the amount and location of melanin in the tissues. V arious stimuli that can result in an increased production of melanin at the level of mucosa include trauma, hormones, radiation and medications. ${ }^{1}$ T obacco used as smoked and smokel ess form induces oral mucosal changes in which intraoral mucosal pigmentation is one of the clinical manifestations. ${ }^{4}$ Smoker's melanosis occurs in up to $21.5 \%$ of smokers. ${ }^{1}$ Smoking may cause increased production of melanin, which may provide a biologic defence against the noxious agents present in tobacco smoke 5 and it is hypothesized that melanin may play a role in detoxification of polycyclic amines, nicotine and benzopyrene. The intensity of the pigmentation is related to the duration and amount of smoking. The changes are symptomless, it is not premalignant, and it seems that the pigmentation is reversible upon smoking cessation. A pigmentation preval ence of about $30 \%$ is seen on the anterior attached gingiva, ${ }^{6}$ the reason can be attributed to fact that the total number of melanophores in the attached gingival is approximately 16 times greater than in the free gingival. ${ }^{7}$ W omen are more commonly affected than men, usually after the third decade of life, which suggests a possible synergistic effect between the female sex hormones and smoking. ${ }^{6}$ Clinically, the lesion usually presents as multiple brown pigmented macules less than $1 \mathrm{~cm}$ in diameter, localized mainly at the attached labial anterior gingival and the interdental papillae of the mandible. The microscopic appearance of melanosis is essentially similar to that seen in physiologic pigmentation or a melanotic macule. Oral melanosis is benign condition but biopsy should be performed if there is surface elevation or increased pigment intensity or pigmentation is in an unexpected site. ${ }^{8}$ In conclusion of study conducted on primary malignant melanoma of oral cavity in J apan with special reference to melanosis, it was suggested that more than one third of the malignant melanomas develop from oral melanosis. The incidence of melanosis associated with oral melanoma was also observed among Caucasians as per reviewed by Chaudhary et $\mathrm{al}^{9}$ and in $50 \%$ of 12 melanomas collected by $M$ oore and $M$ artin, the pigmentation had been present for 1 to 5 years before melanoma developed. ${ }^{10}$ Oral melanosis should be differentiated from ephelis, which is a circumscribed brown macule over skin that has been exposed to sunlight and shows increased melanin pigmentation in the basal cell layer without an increase in the number of melanocytes. ${ }^{11,12}$ Since melanotic macules of the oral mucosa do not exhibit a significant increase in the number of melanocytes, the term lentigo is not considered appropriate for this type of lesion. ${ }^{13}$

\section{CONCLUSION}

Oral melanosis is benign pigmentary lesion of oral mucosa. It is seen more often in smokers. Though it is clinically asymptomatic, but remains a matter of concern to rule out underlying malignancy. Biopsy is considerable if there is surface elevation or increased pigment intensity or pigmentation is in an unexpected site.

\section{REFERENCES}

1. Kauzman A del, Pavone M arisa, Blanas Nick, B radley Grace. Pigmented lesions of the oral cavity: Review, differential diagnosis, and case presentations. J Can Dent Assoc 2004;70(10):682-83.

2. Laidlaw GF, Cahn LR. M elanoblasts in the gum. J Dent Res 1932;12:534-37.

3. Bolognia JL, Orlow SJ. M elanocyte biology. In: B olognia JL, Jorizzo JL, Rapini RP (Eds). Dermatology (2nd ed). London: Mosby 2003:44.

4. Sayed M, M irbod, Stephen I, A hing. Tobacco-associated lesions of the oral cavity (Part I) nonmalignant lesions. J Can Dent A ssoc 2000;66:252-56.

5. Hedin C, Pindborg JJ, Daftary DK, M ehta FS. M elanin depigmentation of the palatal mucosa in reverse smokers: $A$ preliminary study. J Oral Pathol M ed 1992;21(10):440-44.

6. Axell T, Hedin CA. Epidemiologic study of excessive oral melanin pigmentation with special reference to the influence of tobacco habits. Scand J Dent Res 1982;90:434-42. 
7. Patsakas A, Demetriou N, Angelopoulos A. M elanin pigmentation and inflammation in human gingiva. J Periodontol 1981;52(11):701-04.

8. Neville BW, Damm DD, A llen CM, Bouquot JE (Eds). Oral and maxillofacial pathology (2nd ed). Toronto (ON): WB Saunders Company 2002.

9. Chaudhry AP, Hampel A, Gorlin RJ. Primary malignant melanoma of oral cavity: A review of 105 cases. Cancer 1958;11:923-28.
10. M oore ES, M artin $\mathrm{H}$. M elanoma of the upper respiratory tract and oral cavity. Cancer 1955;6:1167-76.

11. Pais S, Hegde SK, Bhat SS. Oral melanotic macule: A case report. J Indian Soc Pedo Prev Dent 2004;22(2):73-75.

12. Trodohl JN, Spragul W G. Benign and malignant mucosa: An analysis of 135 cases. Cancer 1970;25:812-23.

13. Shapiro L, Zegarelli DJ. The solitary labial lentigo: A clinicopathologic study of 20 cases. Oral Surg 1971;31:87-92. 